\title{
Ekonomik Karmaşıklık Gelir Eşitsizliğini Azaltır Mı? Türkiye Ekonomisi Üzerine Ampirik Bir İnceleme
}

$\ddot{O ̈ z}$

Ülkelerin küresel rekabet gücünü artırabilmeleri için bilgi ve teknoloji-yoğunluklu ürünlerin üretilmesi hayati bir öneme sahiptir. Birincil ürünler yerine daha karmaşı üretim süreci gerektiren mal ve hizmetlerin üretilmesi, yarattığı katma değere bağlı olarak ülke ekonomisinde önemli avantajlar sağlamaktadır. Bunun yanında teknoloji-yoğun üretim, nitelikli işgücü gerektirdiği için ekonomik yapıyla beraber kurumsal yapıyı da etkilemektedir. Bu yapı içerisinde insani gelişim açısından adil gelir dağılımı en temel koşulların başında gelmektedir. Üretimdeki bilgi ve teknoloji yoğunluğunu ölçen ekonomik karmaşıklık, ekonomik büyümeyi pozitif etkilemekle birlikte gelir eşitsizliği üzerinde de bazı sonuçlara yol açmaktadır. Bu doğrultuda, Türkiye ekonomisi için 1987-2017 dönemine ait veri seti ile gelir eşitsizliği, ekonomik karmaşıklık ve dışa açıklık göstergeleri arasındaki ilişkinin FMOLS, DOLS ve CCR tahmincileri ile test edilmesi amaçlanmıştır. Kurulan ilk modelde ekonomik karmaşıklık, ekonomik büyüme ve beşeri sermayenin gelir eşitsizliğini azalttığı, nüfusun ise artırdığı sonucuna ulaşılmıştır. İkinci modelin sonuçlarına göre doğrudan yabancı yatırımlar gelir eşitsizliğini artırmakta, ticari açıklık ise azaltmaktadır.

Anahtar Kelimeler: Ekonomik Karmaşıklık, Ekonomik Büyüme, Gelir Eşitsizliği, Gelir Dağılımı, Beşeri Sermaye

\section{Does Economic Complexity Reduce Income Inequality? An Empirical Investigation on Turkish Economy}

\begin{abstract}
The production of knowledge and technology-intensive products is vital for countries to increase their global competitiveness. The products that require a more complex production process instead of primary products create added value and provide various advantages. Besides, because technology-intensive production requires skilled labor, it affects the institutional structure as well as the economic structure. In this structure, fair income distribution is one of the most basic human development conditions. Economic complexity, which measures the intensity of knowledge and technology in production, positively affects economic growth and leads to various consequences on income inequality. In this direction, it was aimed to test the relationship between income inequality, economic complexity, and openness indicators with the data set for the period 1987-2017 by using FMOLS, DOLS, and CCR estimators for the Turkish economy. The first established model concluded that economic complexity, economic growth, and human capital decrease income inequality, whereas the population increases. According to the second model results, foreign direct investments increase income inequality, and trade openness decreases.
\end{abstract}

Keywords: Economic Complexity, Economic Growth, Income Inequality, Income Distribution, Human Capital

Geliş/Received: 30.01 .2021

Kabul/Accepted: 22.06 .2021

* Bu çalışmada kullanılan veriler açık erişimli veri tabanlarından elde edildiği için etik kurul onayı gerektirmemektedir.

\footnotetext{
* Öğr. Gör. Dr., Çukurova Üniversitesi Pozantı Meslek Yüksekokulu, Muhasebe ve Vergi Bölümü, ocengiz@cu.edu.tr, ORCID ID: 0000-0002-1883-4754.

† Dr. Öğr. Üyesi, Erzincan Binali Yıldırım Üniversitesi, İ̈BF İktisat Bölümü, mboga@erzincan.edu.tr, ORCID ID: 0000-0003-2675-2182.

(Makale türü: Araştırma makalesi)
} 


\section{Giriş}

Günümüz ekonomilerinde eşitsizlik, ülkelerin karşılaştığı en önemli sorunların başında gelmektedir. Simon Kuznets (1955), orijinal çalışmasında ekonomik gelişmenin başlangıç aşamalarında gelir eşitsizliğinin artacağını; fakat belirli bir eşik değerinden sonra azalmaya başlayacağını öngörmektedir. Diğer ifadeyle gelir eşitsizliği ile ekonomik büyüme arasında tersU şeklinde bir ilişkinin varlığı söz konusu olmaktadır. Oysa az gelişmiş ve gelişmekte olan ülkelerde, büyümeyle birlikte eşitsizliğinin daha da arttı̆̆ını kanıtlayan bulgular ortaya konulmuştur. Bunun en önemli nedeni, ülkelerin büyüme patikalarının ve yapılarının birbirinden farklı olmasıdır. Daha düşük üretkenliğe sahip ekonomik yapının daha yüksek üretkenliğe geçmesi, ülkeler arasındaki gelişmişlik farkını yansıtmaktadır. Ölçeğe göre getiri seviyesi, talebin gelir esnekliği ve piyasa yapıları arasındaki farklılıklar bu durumu tetiklemektedir. Ekonomik yapıları daha karmaşık olan ülkeler, basit ürünlerde uzmanlaşmaya sahip ülkelerden daha hızlı büyümektedir (Felipe vd., 2012: 36). Dolayısıyla ülkeler arasında kişi başı gelir ve ekonomik gelişme açısından farkın giderek artması, ekonomik karmaşıklığa yönelik ilgiyi artırmıştır.

Hidalgo ve Hausmann'a göre, kökeni Adam Smith’e kadar uzanan ve günümüzde içsel büyüme modellerinde de savunulduğu gibi ekonomik karmaşıklık, ülkeler arasındaki gelir farklılığını açıklamada temel faktördür. Buna göre bir ülkenin üretken yapısındaki değişiklikler, ülkelerin sahip oldukları kapasitelerinin henüz keşfedilmemiş kombinasyonları sonucunda yeni bir ürün bulmaları, yeni kapasite oluşturmaları, bunları mevcut kapasite ile birleştirerek daha fazla ürün geliştirme süreçlerinin bileşiminden oluşmaktadır (2009: 10575).

Ülkelerin bahsedilen üretken kapasitelerini ölçmek için Massachusetts Teknoloji Enstitüsü (MIT) tarafından ürün gruplarına göre Ekonomik Karmaşılık Endeksi (ECI) kullanılmaktadır. Sadece ekonomik büyüklüğü değil, aynı zamanda teknoloji, beşeri sermaye ve kurumsal faktörleri de kapsayan, ülkelerin üretkenlik kapasitelerini ölçebilen ekonomik karmaşıklık endeksi, üretim yapısı ve ekonomik performans arasındaki güçlü korelasyonu göstermektedir (The Observatory of Economic Complexity, 2020).

$\mathrm{Bu}$ çalışmada, ekonomik karmaşıklık ile gelir eşitsizliği arasındaki ilişkinin incelenerek literatüre katkı sağlanması amaçlanmıştır. 1987-2017 dönemi verileriyle Türkiye ekonomisinde ekonomik karmaşıklık endeksinin gelir eşitsizliği üzerindeki etkisi FMOLS, DOLS ve CCR yöntemleriyle araştırılmıştır. Çalışmanın ikinci bölümünde, ekonomik karmaşıklık endeksinin yapısı ve gelir eşitsizliği üzerindeki etkisi ortaya konulmuştur. Üçüncü bölümde, ilgili alanda yapılan çalışmaların bulguları kısaca özetlenmektedir. Dördüncü bölümde veriler, değişkenler ve ampirik metodoloji sunulmaktadır. Çalışmanın beşinci bölümünde, elde edilen bulgulara yer 
verilmekte ve son bölümde ise elde edilen bulgular kapsamında değerlendirmeler ve öneriler ortaya konulmaktadır.

\section{Ekonomik Karmaşıklık Endeksinin Yapısı ve Gelir Eşitsizliği}

Hidalgo ve Hausmann (2009) tarafından inşa edilen ekonomik karmaşıklık endeksi, bir ülkede mevcut olan üretken yetenekler kümesinin bir ölçüsüdür. Bu yetenekler kümesi; beşeri sermaye, teknoloji, kurumlar ve hukukun üstünlüğünü içermektedir (Hidalgo ve Hausmann, 2009).

Bir ekonominin karmaşıklı̆̆, içinde yerleşik olan yararlı bilgilerin çokluğu ile ilgilidir. Karmaşık bir toplumun var olabilmesi ve kendini sürdürebilmesi için tasarım, pazarlama, finans, teknoloji, insan kaynakları yönetimi, operasyonlar ve ticaret hukuku hakkında bilgi sahibi olan insanlar, ürün üretmek için etkileşime girebilmeli ve bilgilerini birleştirebilmelidir. Bu nedenle ekonomik karmaşılık, bir ülkenin üretken çıktısının bileşiminde ifade edilir ve bilgiyi tutmak ve birleştirmek için ortaya çıkan yapıları yansıtır. Toplumun daha fazla miktarda üretken bilgi tutabilmesi ve kullanabilmesi için artan ekonomik karmaşıklığa ihtiyaç duyulmaktadır. Bu durum, ülkelerin üretebileceği ürünlerin kompozisyonundan hareketle ölçülebilmektedir (Hausmann vd., 2011: 18). Bir ülkenin ürünlerinin karmaşıklığı ve çeşitliliği; bilgi çeşitliliği, üretme kabiliyeti ve potansiyel imalat üretiminin varlı̆̆ına bağlıdır. Karmaşık ürünler, temel olarak işgücü veya makineler tarafından sağlanan farklı beceri ve teknik bilgilerle üretilir. Zengin ülkeler, özellikle karmaşık olanlar dâhil çeşitli ürünler üretirken, fakir ülkeler daha az ve daha basit ürünler üretmektedir. Dolayısıyla ürün çeşitliliği ve sayısından hareketle bir ülkenin gelişimini yansıtan ekonomik karmaşıklık endeksinin, ülkenin sahip olduğu bilgi tabanlı teknoloji miktarını ölçtüğü söylenebilir. Ekonomik teknoloji, üretilen ürünlere yansır ve ürünler bir ülkenin ekonomik teknolojisini temsil eder (Moghadasi, 2018: 31).

Ekonomik karmaşıklık endeksinin hesaplanmasında $M_{c p}$ şeklinde bir matris tanımlanmaktadır. Bu matris c ülkesi p ürününü üretiyorsa 1, üretmiyorsa 0 değerini almaktadır. Matrisin satırları veya sütunları toplanarak aşağıdaki şekilde formüle edilmektedir (Hausmann vd., 2011: 24):

$$
\begin{aligned}
& \text { Çeşitlilik }=k_{c, 0}=\sum_{p} M_{c p} \\
& \text { Sıradanlık }=k_{p, 0}=\sum_{c} M_{c p}
\end{aligned}
$$

Çeşitlilik ve sıradanlık matrislerinden sonra belirli bir bölgedeki üretimin ne kadar çeşitli ve farklı ürünlerden oluştuğunu ölçmek amacıyla oluşturulan ekonomik karmaşıklık endeksi (ECI), aşağıdaki matristen hareketle; 


$$
\tilde{M}_{c c^{\prime}}=\sum_{p} \frac{M_{c p} M_{c^{\prime} p}}{k_{c, 0} k_{p, 0}}
$$

Nihai olarak aşağıdaki şekilde oluşmaktadır (Hausmann vd., 2011: 24):

$$
\mathrm{ECI}=\frac{\vec{K}-<\vec{K}>}{\operatorname{Standart} \operatorname{Sapma}(\vec{K})}
$$

$<>$ ortalamayı, $\vec{K}$, ikinci en yüksek özdeğere karşıl1k gelen $\tilde{M}_{c c^{\prime}}$ 'nin özvektörünü ifade etmektedir.

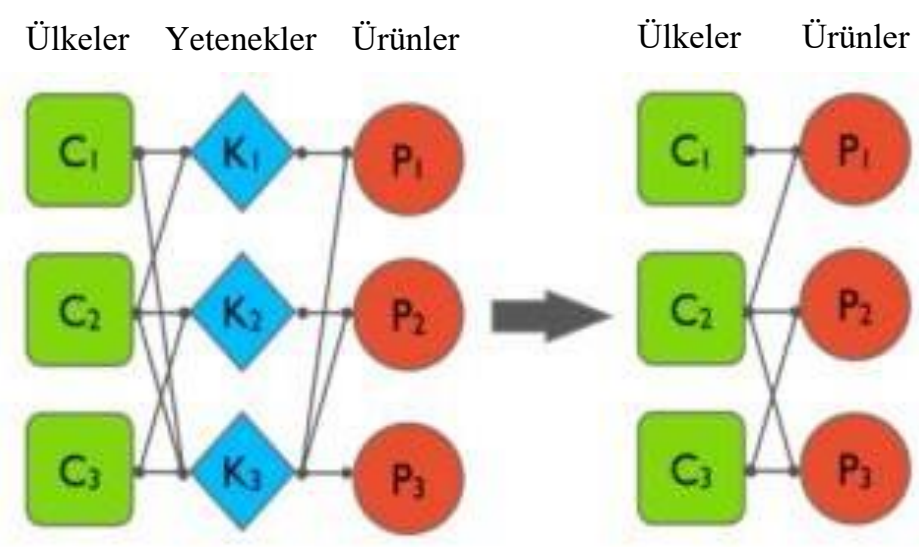

Şekil. Ekonomik Karmaşıklık, Ekonomik Aktörler ve Ekonomik Faaliyet Etkileşimi Kaynak: Cristelli vd., 2017: 8.

Ekonomik karmaşıklığın, ekonomik aktörler (ülkeler) ve ekonomik faaliyetler (ürünler) arasındaki ilişkisi yukarıdaki Şekilde yer almaktadır. Ülkelerarası faktör donatımı farklılığını gösteren yetenekler (mavi elmas), ülkelerin göreceli rekabet gücünü tanımlamaktadır. Ürünlerin niteliği ve sayısı bakımından ülkelerarası üretim farkl11ıkları, sentetik olarak bu rekabetçiliği kodlamaktadır. Çünkü iki taraflı ağ; ülkeler (yeşil kareler), ekonomik çıktı ve faaliyetler tarafından tanımlanmaktadır. Yukarıdaki örnekte, ürünler (kırmızı daireler) üçlü ağ içerisinde yer alan ülkelerin ürünlerinin projeksiyonunu göstermektedir. Bu üçlü modellemenin, heterojen ekonomik boyutların ve ölçülmesi güç etkileşimlerin bir sonucu olan doğrudan bir yaklaşımla sürdürülmesi güçtür. Tersine, ikili ticaret verileri, iki taraflı ağ sonucunda gerçekleştirilen ürünlerin temsili için güçlü bir gösterge sunmaktadır (Cristelli vd., 2017: 8). Buradan yola çıkarak ülke ve ürünlerinin ekonomik karmaşıklık endeksi, i) Ülkede mevcut olan yetenekler kümesinin karmaşıklı̆̆ hakkındaki bilgiyi; ii) Kişi başı gelir düzeyini; iii) Gelecekteki büyüme tahminlerini 
ve iv) Bir ülkenin gelecekteki ihracatının karmaşıklığının tahminini (Hidalgo ve Hausmann, 2009: 10575) ölçmektedir.

Ekonomik karmaşıklığın gelir dağılımını, diğer ifadeyle gelir eşitsizliğini etkilediği birçok mekanizma bulunmaktadır. Hartmann'a göre ekonomik karmaşıklığı yüksek olan ülkelerde, teknolojik ilerlemeler hızlı üretken çeşitlendirme dalgaları, uygun yeni yasal çerçeveler, yeni eğitim kurumları ve yeni teknolojilerin tam potansiyellerini ortaya çıkarmasını sağlayan yeni sosyal ve üretken organizasyon türleri gibi kurumların ortaya çıkmasıyla güçlü bir şekilde bağlantılıdır. Bu yapı, yeni yetenek setleri ve eğitim kurumları gerektirmektedir. Kurumsal yapıdaki değişim ve ulaşımdaki iyileşmeler, insanların daha hareketli olma ve daha fazla bilgiye, seçeneğe erişim imkânlarını artırmaktadır. Nitekim, kalitatif çeşitliliğin yaratılmasıyla birlikte ortaya çıkan kurumsal gelişme, insani gelişme üzerinde daha olumlu bir etki yaratarak eşitsizliği azaltmaktadır (2014: 71).

Karmaşık endüstriyel ürünler, esas olarak kaynak zenginliğine veya düşük işgücü maliyetlerine dayanan basit ürünlerde bulunandan çok daha fazla örtük bilgi ve dağıtılmış bilgi gerektirmektedir. Daha fazla dağıtılmış bilgi ve büyük ölçüde örtük bilgi, yüksek ücretlerin müzakere edilmesinde sendikalaşma ve etkinliğin arttırılması, dolayısıyla ücret eşitsizliğinin azaltılması için teşvikleri artırabilmektedir (Hartmann vd., 2017: 76). Ekonomik karmaşıklık gelir eşitsizliğini azaltmasının yanı sıra insani gelişimi iyileştirmesiyle de, refah seviyesi için kritik öneme sahiptir (Kapartzanis, 2018: 10).

Buna karşılık ekonomik yapıları hammadde ve tarım ürünleri gibi basit ürünlere dayalı olan ülkelerde gelir eşitsizliği çeşitli nedenlerden dolayı artma eğilimindedir. İlk olarak bu ülkelerde çalışanların geliri, ölçeğe göre azalan getiri ve düşük verimlilik ile karakterize edilen ekonomik faaliyetlere bağlıdır. Bunun yanında, nüfusun küçük bir kısmı daha yüksek üretkenliğe sahip sınırlı faaliyetlerden kaynaklanan daha yüksek gelir elde etmektedir. İkinci olarak, bilgi ve becerilerin yayılması küçük birey gruplarıyla sınırlı kalmakta ve diğer bireylerin ekonomik getiriden yoksun kalmalarına yol açmaktadır. Üçüncüsü, gelir dağılımının alt grubunda kalan bireyler sınırlı öğrenme ve mesleki firsatlarla kısıtlanmaktadır. Bu da bireyler arasındaki gelir eşitsizliğini daha da artırmaktadır. Son olarak, birincil ürün üreten ana sektörün varlığı, büyük ölçekteki vasıfsız işçi kadrosunu yönetmek için mesleki yapıdaki dikey hiyerarşiye neden olmaktadır (Lee ve Vu, 2019: 5). Sanayileşmiş ülkelerde ise sanayisizleşme, sendikasızlaşma ve sanayi mallarının ihracatı için artan küresel rekabet, daha yüksek gelir eşitsizliğine katkıda bulunmaktadır (Hartmann vd., 2017: 76).

Ekonomik sistem içerisindeki karmaşıklığın artmasına paralel olarak, belirli uzmanlık gerektiren alanlardaki nitelikli işgücüne duyulan ihtiyaç da artmaktadır. Kapitalist sistem karmaşıklaştıkça çoğalan faaliyetlerin gerçekleştirilmesi için yeni uzmanlıklar ortaya 
çıkmaktadır. Gelişmiş becerilere sahip olan ve hızla öğrenme, adapte olma kapasitesine sahip işgücü gittikçe daha fazla gelir elde etmektedir. Beşeri sermayesi yüksek işgücünün artan nispi önemi, gelir dağılımı üzerinde önemli etkilere sahiptir. Kurumsal, politik ve diğer birçok unsur gelir dağılımını açıkça etkilese de beceri farklılıklarının artması, nitelikli ve deneyimli işçilerin göreli ücretlerinin artması, gelir dağılımı eşitsizliğini etkileyen önemli unsurlardır (Hodgson, 2003: 475-477).

\section{Ampirik Literatür}

Ülkelerin uluslararası ekonomide rekabet edebilmeleri için günümüz koşulları dikkate alındığında ileri teknoloji yoğunluklu ürünlerin üretilmesi birçok alanda avantaj sağlamaktadır. Bilgi yoğunluğu ve beşeri sermayenin önemini ortaya koyan ekonomik karmaşıklık endeksi, ekonomik büyümenin temel kaynaklarından biri haline gelmiştir. Oysa ekonomik karmaşıklığın artması, gelir dağılımı ve insani gelişim gibi kalkınmanın boyutlarını da yakından etkilemektedir. Bu kapsamda, ekonomik karmaşıklık ile ilişkili olan ekonomik büyüme ve gelir eşitsizliğini inceleyen çalışmaların bir kısmının sonuçları aşağıda özetlenerek verilmiştir.

Felipe vd. (2012), Hidalgo ve Hausmann (2009)'1n yansıma yöntemini kullanarak 5107 ürün ve 124 ülkeyi dikkate alarak ürün ve ülke karmaşıklığını ölçmüştür. Yapılan analiz sonucunda şu sonuçlar elde edilmiştir: (i) En karmaşı ürünler makine, kimyasallar ve metallerde, en az karmaşı ürünlerin ise hammadde ve emtia, ahşap, tekstil ve tarımsal ürünlerde tespit edilmiştir. (ii) Dünyadaki en karmaşık ekonomiler Japonya, Almanya ve İsveç ve en az karmaşık olanlar ise Kamboçya, Papua Yeni Gine ve Nijerya'dır. (iii) Daha karmaşık ürünlerin ana ihracatçıları yüksek gelirli ülkelerken, daha az karmaşık ürünlerin büyük ihracatçıları ise düşük gelirli ülkelerdir. (iv) Daha karmaşık ürünlerin ihracat payları gelirle birlikte artarken, daha az karmaşık ürünlerin ihracat payları gelirle birlikte azalmaktadır.

Lapatinas (2016) çalışmasında, ekonomik karmaşıklık ve ihracatın ekonomik büyümenin temel gücü olduğunu teyit eden yaklaşımların, insani gelişsim boyutu açısından geçerli olup olmadığını test etmiştir. 1965-2005 dönemi verileriyle 126 ülke için yapılan tahminde, ekonomik karmaşıklık ile insani gelişim arasında pozitif korelasyon bulunmasına rağmen; herhangi bir nedensellik ilişkisi tespit edilememiştir. Elde edilen bulgulara göre, ekonomik karmaşıklık ekonomik büyümenin kaynağı iken; eğitim, sağlık, mutluluk gibi insani gelişim unsurları üzerinde beklenen etkiye yol açmamaktadır.

Hartmann vd. (2016), 1962-2012 dönemi verileriyle Latin Amerika \& Karayip (LAC) ülkeleri ve Yüksek Performanslı Asya Ekonomileri (HPAE) için yaptığı çalışmada şu bulgulara ulaşmışlardır: i) HPAE'de ekonomik karmaşıklık düzeyinin artması, gelir eşitsizliği üzerindeki 
yapısal kısıtlamaları aşabilmektedir; ii) LAC ülkeleri, doğal kaynak tabanlı üretim yapıları tarafından kısıtlanmakta ve bu yüzden gelir eşitsizliği artmaktadır.

Hartmann vd. (2017)'nin 150'den fazla ülkede 1963-2008 dönemi için ekonomik karmaşıklığın gelir eşitsizliği üzerindeki etkisini araştırdıkları analizde, karmaşık ürünleri ihraç eden ülkelerin basit ürünleri ihraç eden ülkelere kıyasla, daha düşük gelir eşitsizliğine sahip oldukları bulgusuna ulaşmışlardır. $\mathrm{Bu}$ bulgular, bir ülkenin karmaşık üretim yapısının gelir eşitsizliğini sınırlayabileceğine işaret etmektedir.

Zhu ve Li (2017), 210 ülke için yansıma yöntemini kullanarak ekonomik karmaşıklı̆ı ölçtükten sonra, ekonomik karmaşıklık ve beşeri sermayenin ekonomik büyümeye etkisini araştırmıştır. Ekonomik karmaşıklığın ölçümüne ilişkin bulgular, yüksek gelirli ülkelerin ekonomik karmaşıklık endeksinin düşük ve orta gelirli ülkelere göre daha yüksek olduğunu ortaya koymaktadır. Diğer yandan, ekonomik karmaşıklık ve beşeri sermayenin kısa ve uzun vadede ekonomik büyüme üzerinde pozitif etkiye sahip olduğu tahmin edilmiştir. Ayrıca, ekonomik karmaşıklık ile beşeri sermaye etkileşimin kısa ve uzun vadeli büyüme üzerindeki etkisinin büyüklüğü, karş1laştırmalı üstünlük eşiği büyüdükçe arttığı ulaşılan bir diğer bulgudur.

Chávez vd. (2017), Meksika'daki 32 eyalette ekonomik faaliyetlerdeki uzmanlaşmaya bağlı olarak ekonomik karmaşıklığın farklılaştığını ortaya koymuştur. Kuzeydeki eyaletlerin daha yüksek, merkezi eyaletlerin orta düzeyde ve güneydeki eyaletlerin düşük karmaşıklığa sahip olmalarından dolayı, kişi başı gelir düzeyleri de değişmektedir. Dolayısıyla eyaletlerin gelir ile sahip oldukları karmaşıklık düzeyleri arasında pozitif yönlü bir ilişki olduğu ifade edilebilir.

Kapartzanis (2018), ekonomik karmaşıklığın gelir eşitsizliğini negatif etkilediğini öngören yaklaşımların geçerliliğini 227 ülkede 1960-2016 dönemi için test etmiştir. Elde edilen bulgular, ekonomik karmaşıklığın gelir eşitsizliği ile negatif korelasyona sahip olduğunu; fakat aralarında herhangi nedensellik ilişkinin olmadığını göstermektedir.

Gao ve Zhou (2018), 25 ylllık firma verilerini kullanarak 31 eyalette 70 endüstriyi kapsayan veri seti ile Çin için ekonomik karmaşıklık endeksini hesaplayarak, bölgesel ekonomik gelişme ve parasal olmayan ölçümler arasındaki ilişkiyi ele almışlardır. Sonuçlar, kıyı çevresinde bulunan eyaletlerin daha yüksek ekonomik karmaşılılı seviyesine sahip olduğunu göstermektedir. Bununla birlikte ekonomik karmaşıklık, gelir eşitsizliği ile negatif; ekonomik gelişme düzeyi ile pozitif korelasyona sahiptir. Dolayısıyla bu durum, ekonomik karmaşıklığın bölgesel kalkınmada belirleyici role sahip olduğunu göstermektedir.

Moghadasi (2018), 2002-2015 dönemi verileriyle Basra Körfezi ülkeleri için ekonomik karmaşık ve ekonomik büyümenin, enflasyon ve gelir eşitsizliği üzerindeki etkisini araştırmıştır. 
Elde edilen sonuçlara göre ekonomik karmaşıklık ve ekonomik büyüme enflasyon üzerinde anlamlı ve pozitif etkiye sahipken, gelir eşitsizliği üzerinde negatif etkiye sahiptir.

Morais vd. (2018)'nin 2002-2014 periyoduna ait verileri kullanarak Brezilya'daki 27 eyalet için ekonomik karmaşıklığın ücret farklılığına olan etkisini ele aldıkları çalışmanın sonuçlarına göre ekonomik karmaşıklık ile ücret farklılığı arasında ters-U şeklinde lineer olmayan ilişki söz konusudur. Diğer ifadeyle yüksek ekonomik karmaşıklıkla birlikte başlangıçta gelir eşitsizliği artmakta, belirli bir eşik değerinden sonra azalmaya başlamaktadır.

Lee ve Vu (2019), 113 ülke için 1965-2014, 96 ülke için ise 1980-2014 döneminde ekonomik karmaşıklık ile gelir eşitsizliği arasındaki ilişkiyi En Küçük Kareler (EKK) ve GMM yöntemiyle incelemiştir. EKK sonuçları, ekonomik karmaşıklığı daha yüksek olan ülkelerin daha düşük gelir eşitsizliğine sahip olduğunu ve beşeri sermayenin karmaşıklık ile eşitsizlik arasındaki negatif ilişkiyi artırdığını göstermektedir. Ayrıca, ortaokul eğitimi ekonomik karmaşıklıkla etkileşim hususunda yükseköğretimden daha büyük etkiye sahiptir. Buna karşılık, GMM tahmincisi kullanılarak yapılan analizde, ekonomik karmaşıklıktaki bir artışın, daha yüksek gelir eşitsizliği ile ilişkili olduğu bulgusuna ulaşılmıştır.

Fawaz ve Rahnama-Moghadamm (2019), ekonomik karmaşıklık ve gelir eşitsizliği ilişkisini literatürde göz ardı edilen mekânsal bağımlılığın rolünü dikkate alarak analiz etmiştir. Panel veri yöntemiyle 129 ülke için 1964-2013 dönemiyle yapılan tahmin sonuçları, bir ülkedeki gelir eşitsizliğinin, ticaret ortaklarının gelir eşitsizliği ve ekonomik karmaşıklığından etkilendiğini göstermektedir. Buna ilave olarak elde edilen diğer bulgular şu şekildedir: i) Bir ülkenin gelir eşitsizliği, en çok ticaret yaptığı ortakları arasındaki ortalama gelir eşitsizliği ile pozitif korelasyona sahiptir; ii) Ekonomik karmaşıklığı yüksek olan ülkelerle yapılan ticaret, gelir eşitsizliğini azalmaktadır.

Antonelli ve Scellato (2019), ücret eşitsizliğinin teknolojik değişimin nedeni ve sonucu olduğu hipotezini test etmek için 1996-2005 yıllarını kapsayan İtalyan imalat firmalarına ait büyük örneklem verileriyle yaptıkları analiz sonucunda, üretim sürecinin faktör yoğunluğunun firma büyüklüğ̈ ile içsel olduğunu doğrulayan sonuçlara ulaşmışlardır. Buna göre daha düşük birim ücrete sahip küçük firmalar emek yoğun üretim sürecine bağımlıyken, daha yüksek birim ücretlere ve daha düşük sermaye maliyetlerine sahip büyük firmalar ise sermaye yoğun üretim sürecine odaklanmaktadır. Elde edilen bulgular firmaların büyüklüğünün, yüksek sermaye yoğunluğu gerektiren üretim sürecindeki ücretlerin ve ortalama ücretlerin, sermaye yoğunluğu tarafından belirlendiğini göstermektedir. 
Şeker (2019), uluslararası rekabet üstünlüğünün sağlanması açısından, teknolojik gelişme ve yüksek teknoloji ihracatının günümüz ekonomilerindeki öneminden hareketle ekonomik karmaşıklık endeksinin teknolojik gelişme, yüksek teknolojili ürün ihracatı ve sermaye yatırımları arasındaki ilişkiyi 1989-2017 periyodu verileriyle Türkiye için incelemiştir. Yapılan eşbütünleşme testleri, ekonomik karmaşıklık endeksi ile yüksek teknolojili ürün ihracatı, yerli patent başvuruları ve sabit sermaye yatırımları arasında uzun dönemli bir ilişkinin varlığını ortaya koyarken, nedensellik sonuçları ise değişkenlik göstermektedir. Örneğin, ekonomik karmaşıklık endeksi, yüksek teknolojili ürün ihracatı ve yerli patent başvuruları arasında çift yönlü, brüt sabit sermaye yatırımlarından ekonomik karmaşıklık endeksi, yüksek teknolojili ürün ihracatı ve yerli patent başvurularına doğru ise tek yönlü nedensellik söz konusudur.

Le Caous ve Huarng (2020), Birleşmiş Milletler Kalkınma Programı kapsamında sürdürülebilir kalkınma hedeflerine ulaşmada ekonomik karmaşıklık endeksi ile insani gelişim endeksi ilişkisini gelir eşitsizliğinin aracılık etkisini de dikkate alarak, gelişmekte olan 87 ülkede 1990-2017 periyodu verileriyle incelemiştir. Elde edilen bulgular, beşeri gelişmenin ekonomik karmaşıklıkla birlikte arttığını; fakat bu ilişkiye gelir eşitsizliğinin aracılık ettiğini göstermektedir. Ayrıca ülke düzeyindeki tahminler incelendiğinde cinsiyet eşitsizliği ve enerji tüketimi sürdürülebilir kalkınmayı etkilemektedir.

Zhu vd. (2020), Çin'de ihraç ürünlerinin ve destinasyon yapılarının karmaşıklığının gelir eşitsizliğine olan etkisini kent-kır ayrımı özelinde incelemiştir. Elde edilen bulgular, ihraç ürünü/destinasyon yapılarının karmaşıklığı ile gelir eşitsizliği arasındaki zıt yönlü ilişkinin, sadece Çin'in kentsel alanlarında mevcut olduğunu; buna karşıllk kırsal alanlarda geçerli olmadığını göstermektedir. Kent-kır ayrımı çerçevesinde ele alındığında, ihracatın geliştirilmesinin faydaları kentsel alanlarla sınırlı kalmıştır.

Ekonomik karmaşıklık endeksinin ekonomik büyümeyi pozitif yönde etkilediğine yönelik genel bir mutabakatın olduğu ifade edilebilir. Ancak literatürde ekonomik karmaşıklıkla elde edilen gelirin toplumda adil dağılıp dağılmadığını inceleyen çalışmalar mevcut olmakla birlikte genel eğilime bakıldığında, bunun sınırlı olduğu görülmektedir. Ulusal literatürde ise söz konusu değişkenler arasındaki ilişkiyi inceleyen çalışmalar yok denecek kadar azdır. Bu çalışmada, Türkiye için ekonomik karmaşıklığın gelir eşitsizliği üzerindeki etkisi, dışa açıklığın rolü de dikkate alınarak iki farklı model kapsamında incelenmiştir. Böylelikle özgün bakış açısının geliştirilmesi noktasında, literatürdeki boşluğun doldurulması amaçlanmıştır.

\section{Veri, Model ve Yöntem}

Bu çalışmada, 1987-2017 yılları için Türkiye ekonomisinde gelir eşitsizliği ile ekonomik karmaşıklık endeksi arasındaki ilişkinin tespit edilmesi amaçlanmaktadır. Verilere erişimde yaşanan kısıtlar nedeniyle ampirik analiz, 1987-2017 dönemini kapsamaktadır. Üretim 
yapılarının yetkinlik, karmaşıklık ve büyüklük durumunu gösteren ekonomik karmaşıklık endeksinin gelir eşitsizliği üzerindeki etkisi araştırılırken, kurulan ampirik modele gelir eşitsizliğini etkileyebileceği düşünülen önemli göstergeler kontrol değişkenleri olarak eklenmiştir.

Bu doğrultuda modele, ekonomik büyüme [Aiyar ve Ebeke (2019), Vo vd. (2019), Nwosa (2019), Brida vd. (2020)], beşeri sermaye endeksi [ Lee ve Vu (2019), Feng ve Tang (2019)], toplam nüfus [Bor vd. (2017), Butler vd. (2020)], dışa açıklık [Goh ve Law (2019), Chyi ve Su (2020)] ve doğrudan yabancı yatırımlar [Kaulihowa ve Adjasi (2018), Khan ve Nawaz (2019)] kontrol değişkeni olarak modele eklenmiştir. Belirlenen kontrol değişkenleri ile birlikte Lee ve $\mathrm{Vu}$ (2019)'nun çalışmalarını takiben ekonometrik model şu şekilde oluşturulmuştur:

$$
\left(\mathrm{GINI}_{\mathrm{it}}\right)=\mathrm{f}\left(\mathrm{GDP}_{\mathrm{it}}, \mathrm{ECI}_{\mathrm{it}}, \mathrm{HC}_{\mathrm{it}}, \mathrm{POP}_{\mathrm{it}}, \mathrm{FDI}_{\mathrm{it}}, \mathrm{TR}_{\mathrm{it}}\right)
$$

(1) nolu denklemde yer alan değişkenler ve açıklamaları Tablo 1'de yer almaktadır.

Tablo 1. Değişkenlerin Tanımı

\begin{tabular}{|c|c|c|}
\hline Değişken & Kapsamı & Kaynak \\
\hline GINI & $\begin{array}{l}\text { Gini endeksi, bir ekonomideki } \\
\text { bireyler veya hane halkları arasında } \\
\text { gelir dağılımının ne kadar eşit } \\
\text { dağıldığını ölçmektedir. }\end{array}$ & Solt (2019) \\
\hline GDP & $\begin{array}{l}2010 \text { fiyatlarıyla ABD \$ cinsinden } \\
\text { Gayrisafi Yurtiçi Hasılayı ifade } \\
\text { etmektedir. }\end{array}$ & theglobaleconomy.com \\
\hline ECI & $\begin{array}{l}\text { Üretken teknik bilgi birikimine, } \\
\text { özellikle de karmaşık uzmanlık } \\
\text { bilgisine ve teknolojiye dayalı } \\
\text { olarak üretilen ürünlerin kalitesini } \\
\text { ölçmektedir. }\end{array}$ & $\begin{array}{c}\text { The Observatory of Economic } \\
\text { Complexity }\end{array}$ \\
\hline $\mathrm{HC}$ & $\begin{array}{l}\text { Ortalama eğitim süresi ve eğitimin } \\
\text { getirisine dayanarak oluşturulan kişi } \\
\text { başı beşeri sermaye endeksini ifade } \\
\text { etmektedir. }\end{array}$ & Penn World Table \\
\hline POP & Toplam nüfusu ifade etmektedir. & theglobaleconomy.com \\
\hline FDI & $\begin{array}{l}\text { Net doğrudan yabancı yatırım } \\
\text { girişlerinin GSYİH içerisindeki } \\
\text { payını göstermektedir. }\end{array}$ & theglobaleconomy.com \\
\hline TR & $\begin{array}{l}\text { Dışa açıklığı temsilen ihracat ile } \\
\text { ithalatın toplamının GSYİH } \\
\text { içindeki payını göstermektedir. }\end{array}$ & theglobaleconomy.com \\
\hline
\end{tabular}

Yapılan ampirik analizde dışa açıklığın gelir eşitsizliği üzerindeki net etkisinin ortaya konulması amacıyla iki farklı model kurularak analiz yapılmıştır. Modelde yer alan değişkenlerin tamamının logaritmik formu aşağıdaki gibidir:

\section{Model I}

$$
\operatorname{Ln}\left(\mathrm{GINI}_{i t}\right)=\beta_{0}+\beta_{1} \operatorname{LnGDP}_{i t}+\beta_{2} \mathrm{LnECI}_{i t}+\beta_{3} \mathrm{LnHC}_{i t}+\beta_{4} \mathrm{LnPOP}_{i t}+c_{i t}
$$




\section{Model II}

$$
\begin{aligned}
& \operatorname{Ln}\left(\mathrm{GINI}_{\text {it }}\right)=\beta_{0}+\beta_{1} \mathrm{LnGDP}_{\text {it }}+\beta_{2} \operatorname{LnECI}_{\text {it }}+\beta_{3} \mathrm{LnHC}_{\text {it }}+\beta_{4} \operatorname{LnPOP}_{\text {it }}+\beta_{5} \operatorname{LnFDI}_{\text {it }}+ \\
& \beta_{5} \mathrm{LnTR}_{\text {it }}+c_{\text {it }}
\end{aligned}
$$

Değişkenler arasındaki ilişkinin test edilmesi aşamasında ilk olarak birim kök sınamasının yapılması gerekmektedir. Değişkenlerin birim kök sınamasında Zivot ve Andrews (1992) tarafından geliştirilen birim kök testinden faydalanılmıştır. Zivot ve Andrews (1992) testi, tek kırılmaya izin veren toplamda üç modelden (Model A, B ve C) faydalanarak hipotezlerin test edilmesini sağlayan bir sınama yöntemidir. Modellerin boş hipotezi;

$$
\begin{aligned}
& \text { Model (A): } y_{t}=\mu+d D\left(T_{B}\right)_{t}+y_{t-1}+\varepsilon_{t} \\
& \text { Model (B): } y_{t}=\mu+y_{t-1}+\left(\mu_{2}-\mu_{1}\right) D U_{t}+\varepsilon_{t} \\
& \text { Model (C): } y_{t}=\mu+y_{t-1}+d D\left(T_{B}\right)_{t}+\left(\mu_{2}-\mu_{1}\right) D U_{t}+\varepsilon_{t}
\end{aligned}
$$

Hipotezlere göre, $D\left(T_{B}\right)_{t}=1$ olması durumunda, $\mathrm{t}=T_{B}+1$, olmaması durumunda 0 , $D U_{t}=1$ ise, $\mathrm{t}>T_{B}$, aksinde $0 \mathrm{D} T^{*}=t-T_{B}$ ise $\mathrm{t}>T_{B}$ olmamas1 durumunda ise 0 kabul edilir. Model (A) serinin düzey değerindeki egzojen değişimleri gösterirken, Model (B) ortalama meydana gelen egzojen değişimleri, Model (C) ise her ikisinde meydana gelen değişimleri göstermektedir (Zivot ve Andrews, 1992: 253).

Birim kök sınaması sonrası birinci farkında [I(1)] durağan olan seriler için eşbütünleşme testinin yapılması gerekmektedir. Aynı düzeyde durağanlık gösteren serilerin aralarında uzun dönemli ilişki olup olmadığının test edilmesi için eşbütünleşik bir özelliğe sahip olması gerekmektedir. Değişkenler arasındaki eşbütünleşme ilişkisinin tespit edilmesi amacıyla Johansen (1988), Johansen ve Juselius (1990) tarafından geliştirilen Johansen eşbütünleşme testi kullanılmıştır. $\mathrm{Bu}$ teste göre belirlenen seriler arasındaki eşbütünleşme sayısına $\mathrm{q}=\mathrm{r}$ eşitliği ve alternatif hipotezine göre iki farklı istatistiğe göre karar verilmektedir. Değişkenler arasında eşbütünleşme ilişkisi yoktur şeklinde boş hipotezi olan testin iki temel iz ve maksimum öz değer olmak üzere iki istatistiği söz konusudur. Testin iz değer istatistiği;

$\operatorname{Tr}=-\mathrm{T} \sum_{i=r+1}^{p} \ln (1-\hat{\lambda})_{t}$ ile hesaplanır.

$\hat{\lambda}$ p-r düzeydeki en küçük değeri, r en yüksek eş bütünleşme vektörünü ifade etmektedir.

Alternatif hipotezdeki maksimum özdeğer istatistiği ise;

L-max $=-\operatorname{TLn}\left(1-\hat{\lambda}_{r}\right.$ ile hesaplanır. Bu testin temel hipotezi $\mathrm{r}=0$ şeklinde iken alternatif hipotez $\mathrm{r}=1$ şeklinde sıralanır ve bu test için maksimum gecikme uzunluğunun belirlenmesi oldukça önemlidir (Zortuk, 2009: 235).

Birim kök testi ve eşbütünleşme ilişkisinin tespit edilmesi sonrasında uzun dönem katsayı tahmincilerinden FMOLS (Fully Modified Ordinary Least Squares), DOLS (Dynamic Ordinary 
Least Squares) ve CCR (Canonical Cointegrating Regression) tahmincilerinden faydalanılmıştır. Bu yöntemlerin sıfır hipotezi, “değişkenler arasında uzun dönemli ilişki yoktur” şeklindedir.

Phillips ve Hansen (1990) tarafından geliştirilen yarı parametrik olan FMOLS tahmincisi küçük örnekleme sahip olan analizler de dâhil endojenlik ve otokorelasyon gibi sorunları çözebilen bir yöntemdir. FMOLS yöntemi;

$\hat{Q}_{M E}=1 /\left(\sum_{t=1}^{T} Z_{t} Z_{t}\right)\left(\sum_{t=1}^{T} Z_{t} Y_{t}{ }^{+}-T\left[\begin{array}{c}\mathfrak{X}_{12}^{\prime} \\ 0\end{array}\right]\right)$ denklemi ile hesaplanmaktadir.

$Y_{t}^{+}, \hat{X}_{12}^{\prime}$ terimleri endojenite ve otokorelasyon için düzeltme terimini ifade etmektedir.

$\mathrm{Bu}$ tahmincide, ölçüm tahmincisi asimptotik olarak tarafsızdır ve asimptotik chi-kare istatistiksel çıkarım kullanılarak standart Wald testlerine izin veren normal asimptotik dağılıma sahiptir (Adom vd., 2015: 31).

Stock ve Watson (1993) tarafından geliştirilen parametrik bir tahminci olarak DOLS yöntemi ise, OLS yönteminde ortaya çıkan otokorelasyon ve endojenite sorunlarını çözmektedir. Genel olarak DOLS yöntemi,

$$
Y_{t}=\alpha_{0}+\alpha_{1 t}+\alpha_{2} X_{t}+\complement_{t=q} \delta_{i} \Delta X_{t-i}+e_{t} \text { şeklinde hesaplanır. }
$$

$\mathrm{y}$, bir zaman serisini, $\mathrm{t}$, zaman periyodunu, $\mathrm{x}$, bağımsız değişken/leri $\mathrm{q}$, optimal gecikme uzunluğunu, $\Delta$ fark operatörünü ve $\varepsilon$ hata terimini göstermektedir (Bulut, 2017: 15422).

Park (1992) tarafından geliştirilen CCR yöntemi, uzun dönem kovaryans matrisi,

$$
\begin{gathered}
y_{t}=\alpha^{\prime} X_{t}+e_{t} \\
y_{t}=\pi^{\prime} c_{t}+\alpha^{\prime} X_{t}+e_{t} \quad \pi=\pi_{1}-\pi_{2} \alpha
\end{gathered}
$$

şeklinde ifade edilir (Park, 1992: 125).

\section{Bulgular}

Çalışmanın ilk aşamasında uygulanan birim kök sınamasına ait test bulguları Tablo 2'de yer almaktadır. Bu testten elde edilen bulgular Model C'ye dayalı istatistik bulgularıdır.

Tablo 2. Zivot ve Andrews Birim Kök Testi Bulguları

\begin{tabular}{ccc}
\hline Değ ģşkenler & $\boldsymbol{t}$-istatistiği & Kırılma Tarihi \\
\hline $\operatorname{lnGINI}$ & -4.316 & 1997 \\
$\operatorname{lnECI}$ & -1.681 & 2013 \\
$\operatorname{lnGDP}$ & -3.308 & 2002 \\
$\operatorname{lnHC}$ & -3.261 & 2008 \\
$\operatorname{lnTR}$ & -4.606 & 1994 \\
LnFDI & -3.455 & 2009 \\
LnPOP & -3.117 & 1999 \\
$\Delta \operatorname{lnGINI}$ & $-6.664^{* * *}$ & 1995 \\
$\Delta \operatorname{lnECI}$ & $-8.825^{* * *}$ & 2006 \\
$\Delta \ln \mathrm{GDP}$ & $-6.009^{* * *}$ & 2004 \\
$\Delta \operatorname{lnHC}$ & $-6.746^{* * *}$ & 2006 \\
$\Delta \operatorname{lnTR}$ & $-6.715^{* * *}$ & 1998
\end{tabular}




\begin{tabular}{ccc}
\hline & & \\
$\Delta \operatorname{lnFDI}$ & $-5.827 * * *$ & 2005 \\
$\Delta \ln P O P$ & $-5.068 * * *$ & 2006 \\
\hline
\end{tabular}

Not: Uygulanan birim kök testinin kritik değerleri: \% 1: -5.57, \% 5: -5.08, \% 10: -4.82. *** \% 1 düzeyinde istatistiki anlamlılı̆̆ 1 ifade etmektedir.

Elde edilen bulgulara göre, serilerin düzey değerlerinde birim kök içerdiğini ifade eden sıfır hipotezi reddedilemezken, serilerin fark değerleri için sıfır hipotezinin reddedildiği görülmektedir. Diğer bir ifadeyle serilerin birinci farkında durağan [(1)] olduğu söylenebilir. Birinci farkında durağan olan serilerden oluşan her iki model için uygulanan eşbütünleşme testi bulguları ise Tablo 3'te yer almaktadır.

Tablo 3. Johansen Eşbütünleşme Testi Bulguları

\begin{tabular}{lccccc}
\hline Model & Ho & İz Dĕger & $\begin{array}{c}\text { Johansen Eşbütünleşme Testi } \\
\text { Kritik Değerler } \\
\mathbf{( \% 5 )}\end{array}$ & $\begin{array}{c}\text { Maximum Öz } \\
\text { Değerler }\end{array}$ & $\begin{array}{c}\text { Kritik Değerler } \\
\mathbf{( \% 5 )}\end{array}$ \\
\hline \multirow{2}{*}{ Model I } & & 69.81889 & 43.45573 & 33.87687 \\
& $\mathrm{r}=0$ & 92.04787 & 47.85613 & 25.20810 & 27.58434 \\
& $\mathrm{r} \leq 1$ & 48.59214 & 29.79707 & 12.42073 & 21.13162 \\
& $\mathrm{r} \leq 3$ & 23.38404 & 15.49471 & 6.794637 & 14.26460 \\
& $\mathrm{r} \leq 4$ & 4.168671 & 3.841466 & 4.168671 & 3.841466 \\
\hline \multirow{3}{*}{ Model II } & $\mathrm{r}=0$ & 198.7217 & 125.6154 & 59.85536 & 46.23142 \\
& $\mathrm{r} \leq 1$ & 138.8664 & 95.75366 & 45.09657 & 40.07757 \\
& $\mathrm{r} \leq 2$ & 93.76981 & 69.81889 & 39.45754 & 33.87687 \\
& $\mathrm{r} \leq 3$ & 54.31227 & 47.85613 & 26.88825 & 27.58434 \\
& $\mathrm{r} \leq 4$ & 27.42402 & 29.79707 & 18.25034 & 21.13162 \\
& $\mathrm{r} \leq 5$ & 9.173682 & 15.49471 & 6.694550 & 14.26460 \\
& $\mathrm{r} \leq 6$ & 2.479132 & 3.841466 & 2.479132 & 3.841466 \\
\hline
\end{tabular}

Elde edilen bulgulara göre, Model I ve Model II için seriler arasında "eşbütünleşme yoktur" şeklindeki sıfır hipotezinin reddedildiği ve seriler arasında eşbütünleşme olduğu bulgusuna ulaşılmıştır. Elde edilen bu sonuç, değişkenlerin uzun dönemde birlikte hareket ettiğini ve değişkenler arasındaki uzun dönemli ilişkinin araştırılmaya uygun olduğunu göstermektedir. Uzun dönem katsayılarına ilişkin bulgular Tablo 4'te yer almaktadır.

Tablo 4. Uzun Dönem Katsayıları

\begin{tabular}{|c|c|c|c|}
\hline Değişkenler & FMOLS & DOLS & CCR \\
\hline \multicolumn{4}{|l|}{ Model I } \\
\hline LnGDP & $-0.003 *$ & $-0.007 * * *$ & $-1.170 * * *$ \\
\hline LnECI & $-0.006^{* *}$ & $-0.040 * * *$ & $-0.003 * * *$ \\
\hline LnHC & $-0.673 * *$ & $-0.166 * * *$ & $-0.171 * * *$ \\
\hline LnPOP & $0.447 * *$ & $0.003 * * *$ & $0.003 * * *$ \\
\hline Sabit Terim & $1.233 * * *$ & $1.769 * * *$ & $1.765 * * *$ \\
\hline \multicolumn{4}{|l|}{ Model II } \\
\hline LnGDP & $-0.037 * * *$ & $-0.081 * *$ & -0.330 *** \\
\hline LnECI & $-0.028 * * *$ & $-0.040 * * *$ & $-0.032 * * *$ \\
\hline LnHC & $-0.234 * * *$ & $-0.262 * * *$ & $-0.177 * * *$ \\
\hline LnPOP & $0.005^{* *}$ & $0.006^{* * *}$ & $0.475^{* * *}$ \\
\hline LnFDI & $0.0007 * *$ & $0.002 *$ & $0.004 * * *$ \\
\hline LnTR & $-0.001 * *$ & $-0.007 * * *$ & $-0.002 * * *$ \\
\hline Sabit Terim & $1.997 * * *$ & $2.206 * * *$ & $1.145^{* * *}$ \\
\hline
\end{tabular}

Not: $*, * *$ ve *** sırasılla $\% 10, \% 5$ ve $\% 1$ düzeyinde istatistiki anlamlılığı ifade etmektedir. 
Elde edilen bulgularda, her üç tahminciye göre birinci modelde uzun dönemde ekonomik büyüme, ekonomik karmaşıklık ve beşeri sermayenin gelir eşitsizliğini negatif, toplam nüfusun ise pozitif yönde etkilediği görülmektedir. Dışa açıklık göstergelerinin yer aldığı Model 2'ye göre ise doğrudan yabancı yatırımlar gelir eşitsizliğini pozitif, ticari açıklık ise negatif yönde etkilemektedir.

\section{Sonuç ve Değerlendirme}

21. yüzyıldaki küresel ekonomik yapılanma dikkate alındığında ihracata konu olan ürün çeşitliliği ve kompozisyonu yanında, ürünlerin yapısı önem kazanan hususlardan birisi olmuştur. Ülkelerin ürettiği ürünlerin bilgi, teknoloji ve beşeri sermaye yoğunluğunu ifade eden ekonomik karmaşıklık endeksi, uluslararası rekabetin sürdürülebilirliği konusunda oldukça önemlidir. Ülkeler karmaşık yapıdaki ürünleri üretebilmek için teknolojiye yönelik yatırımlarla birlikte teknolojik gelişimi sağlayacak ve üretim sürecinde ihtiyaç duyulan nitelikli işgücü talebini karşılayabilmek için beşeri sermaye yatırımlarını da artırmaktadır. Üretim yapısındaki bu değişiklik, ekonomik büyümenin temel gücü haline gelmektedir. Büyümeyle birlikte öne çıkan diğer bir husus, gelirin adil dağılımına yöneliktir. Ekonomik karmaşıklık, sofistike üretim sürecine dahil olan beşeri sermayesi yüksek işgücü için nispi olarak daha yüksek ücret düzeyleri ile çeşitli avantajlar sağlamasına rağmen, düşük vasıflı işgücü aleyhine gelir eşitsizliğinin artmasına yol açmaktadır. Buna karş1lık karmaşık üretim yapısı teknolojik dönüşüm yanında kurumsal kalitenin iyileşmesini ve mobilizasyon fırsatlarının artmasını sağlayarak, gelir eşitsizliği azaltmaktadir.

Bu kapsamdan yola çıkarak çalışmada, Türkiye ekonomisi için 1987-2017 dönemi verileri kullanılarak ekonomik karmaşıklık ile gelir eşitsizliği arasındaki ilişki analiz edilmiştir. Esas olarak ekonomik karmaşıklık ile gelir eşitsizliği ilişkisine odaklanılmakla birlikte, dışa açıklı (liberalizasyon) göstergelerinin net etkisinin tespit edilmesi amacıyla iki ayrı model kurulmuştur. Zira ekonomik karmaşıklık endeksinin aynı zamanda ülkelerin ihracatı içerisinde bilgi ve teknoloji yoğun ürünlerin payını da ifade etmesi açısından dışa açıklık bu noktada önemli bir husustur. FMOLS, DOLS ve CCR tahmincileri kullanılarak elde edilen bulgulara göre her iki modelde yer alan ekonomik büyüme, ekonomik karmaşıklık ve beşeri sermaye değişkenleri gelir eşitsizliğini azaltırken, toplam nüfus eşitsizliği artırmaktadır. Bunun yanında ikinci modelde yer alan değişkenlerden doğrudan yabancı yatırımlar gelir eşitsizliğini pozitif, ticari açıklık ise negatif etkilemektedir. Diğer ifadeyle, doğrudan yabancı yatırımların payının artması eşitsizliği artırmakta, ihracat ve ithalatın milli gelirdeki payının artması ise eşitsizliği azaltmaktadır. 
Kurulan her iki modelde yer alan ve çalışmanın odak noktasını oluşturan ekonomik karmaşıklık ve gelir eşitsizliği ilişkisine ait elde edilen bulgular, Hartmann vd. (2017), Moghadasi (2018) ve Kapartzanis (2018) gibi yazarların çalışmalarıyla tutarlıdır.

Elde edilen sonuçlar değerlendirildiğinde dünyanın en büyük ilk yirmi ekonomisinden biri olan Türkiye'nin ileri teknoloji gerektiren ürünlerin üretiminde ilerlemeler kaydetmesinin bir gereklilik olduğu ortaya konulmuştur. Kaynakların uluslararası rekabet gücünü artıracak alanlara yönlendirilerek, katma değeri yüksek ürünler üretilmesi ve ihraç edilmesi makroekonomik alanda iyileştirmeler sağlaması yanında, gelir eşitsizliğini azaltarak insani gelişime de katk1 sağlamaktadır. Çünkü gelir dağılımının daha adil hâle gelmesiyle bireylerin daha iyi eğitim, sağlık, kültür gibi alanlara yönelik harcamalara erişim olanakları artmakta ve ekonomik karmaşıklığın en önemli bileşeni olan beşeri sermaye yatırımları artış göstermektedir.

$\mathrm{Bu}$ durum, teknolojik ürünler gibi karmaşık ürünlerin üretiminin, güçlü kurumların ve teknik bilginin somutlaştığı işgücünün varlığını ifade eden beşeri sermayenin olduğu ülkelerde gerçekleştiği dikkate alındığında (Hidalgo, 2015), daha önemli hâle gelmektedir. Dolayısıyla bir ekonomideki karmaşık endüstrilerin varlığı, o ülkenin kurumlarının kapsayıcılığını ve nüfusunda somutlaşan bilgi birikimini yansıtmaktadır (Hartmann vd., 2017).

Dışa açılılı göstergeleri olarak incelenen doğrudan yabancı yatırım ile ihracat ve ithalatın toplamının milli gelir içerisindeki payının gelir eşitsizliği üzerindeki etkisi farklılaşmaktadır. Doğrudan yabancı yatırımlar açısından ele alındığında, sermaye akışının genellikle nitelikli işgücünün yüksek olduğu ülkeyi tercih ettiği ve nitelikli işgücünün ücretlerinde meydana gelen artışın düşük vasıflı işgücüyle oluşan ücret farklılığını artırdığı görülmektedir. Bu noktada ilerici sosyal transferler gibi gelir dağılımının iyileştirilmesi konusunda kullanılacak kamusal politikaların rolü önem kazanmaktadır. Beşeri sermaye farklılığından kaynaklanan gelir eşitsizliğinin azaltılması için uygulanacak sosyal transferler, eğitim koşullarını iyileştirerek sadece eşitsizliği azaltmamakta bunun yanında doğrudan yabancı yatırımlar için gerekli olan nitelikli işgücü arzını da artırmaktadır (Herzer vd., 2014: 790). Dolayısıyla Türkiye'de karmaşık üretim yapısının gelir dağılımını iyileştirici etkisinin yatırım girişlerinin gelir dağılımı üzerindeki olumsuz etkisiyle bertaraf edilmemesi için politikaların dengeli olması gerekmektedir. Özellikle beşeri sermaye gelişimini artıracak kamusal eğitim politikaları, nitelikli ve düşük vasıflı işgücü arasındaki açığı kapatabilir. Ticari açıklık ise doğrudan yabancı yatırımların tersine gelir eşitsizliğini azalmaktadır. Ticari açıdan dışa açılmanın doğrudan yabancı yatırımlar gibi belirli firma, sektör veya bölgeye yönelik olmayıp daha kapsayıcı olmasından dolayı ticaret kazançlarından eşit ölçüde yararlanma koşulları daha fazladır.

Türkiye'nin birçok açıdan yüksek gelişme potansiyeli göz önüne alınarak bulguların genel bir değerlendirmesi yapılırsa, ileri teknoloji ve beşeri sermaye gerektiren ürünlerin gelir 
eşitsizliği üzerindeki pozitif etkisi dışa açılmayla desteklenmektedir. Fakat doğrudan yabancı yatırım girişlerinin, işgücü arasındaki nitelik farkından kaynaklanan olumsuz etkisinin, gelir dağılımda sağlanan iyileşmeleri sınırlamaması için kamusal eğitim politikaları da devreye sokulmalıdır.

Yazar Katkıları: Bu çalışmanın ilk iki bölümüyle birlikte ampirik literatür araştırması bölümünde birinci yazar Orhan CENGIZ, verilerin elde edilmesi ve analizinde ise ikinci yazar Müge MANGA katkı sağlamıştır.

Çıkar Beyanı: Yazarlar arasında herhangi bir çıkar çatışması bulunmamaktadır.

\section{Kaynakça}

Adom, P. K., Amakye, K., Barnor, C. ve Quartey, G. (2015). The Long-Run Impact of Idiosyncratic and Common Shocks on Industry Output in Ghana. OPEC Energy Review, 39(1), 17-52.

Aiyar, S. S. ve Ebeke, C. (2019). Inequality of Opportunity, Inequality of Income and Economic Growth. IMF Working Paper WP/19/34, 1-24.

Antonelli, C. ve Scellato, G. (2019). Wage Inequality and Directed Technological Change: Implications for Income Distribution. Technological Forecasting \& Social Change, 141, 59-65.

Bor, J., Cohen, G. H. ve Galea, S. (2017). Population Health in An Era of Rising Income Inequality: USA, 1980-2015. The Lancet, 389(10077), 1475-1490.

Brida, J. G., Carrera, E. J. S. ve Segarra, V. (2020). Clustering and Regime Dynamics for Economic Growth and Income Inequality. Structural Change and Economic Dynamics, 52, 99-108.

Bulut, U. (2017). The Impacts of Non-Renewable and Renewable Energy on $\mathrm{CO}_{2}$ Emissions in Turkey. Environmental Science and Pollution Research, 24(18), 15416-15426.

Butler, J. L., Wildermuth, G., Thiede, B. C. ve Brown, D. L. (2020). The Dynamics of Population Change and Income Inequality in Rural America. Doi: https://doi.org/10.31235/osf.io/g3yhe.

Chávez, J. C., Mosqueda, M. T. ve Gómez-Zaldívar, M. (2017). Economic Complexity and Regional Growth Performance: Evidence from the Mexican Economy. Review of Regional Studies, 47(2), 201-219.

Chyi Y. L. ve Su, Y. H. (2020). Technology Progress, Trade Openness, and Income Inequality: A Cross-Country Empirical Study. Tsounis N., Vlachvei A. (Eds), Advances in CrossSection Data Methods in Applied Economic Research. ICOAE 2019. Springer Proceedings in Business and Economics (pp. 491-506). Springer, Cham.

Cristelli, M., Tacchella, A., Cader, M., Roster, K. ve Pietronero, L. (2017). On the Predictability of Growth. The World Bank Policy Research Working Paper 8117, 1-45.

Fawaz, F. ve Rahnama-Moghadamm, M. (2019). Spatial Dependence of Global Income Inequality: The Role of Economic Complexity. The International Trade Journal, 33(6), 542-554.

Felipe, J., Kumar, U., Abdon, A. ve Bacate, M. (2012). Product Complexity and Economic Development. Structural Change and Economic Dynamics, 23(1), 36-68. 
Feng, S. ve Tang, G. (2019). Accounting for Urban China's Rising Income Inequality: The Roles of Labor Market, Human Capital, and Marriage Market Factors. Economic Inquiry, 57(2), 997-1015.

Gao, J. ve Zhou, T. (2018). Quantifying China's Regional Economic Complexity. Physica A: Statistical Mechanics and Its Applications, 492, 1591-1603.

Goh, L. T. ve Law, S. H. (2019). The Effect of Trade Openness on Income Inequality with the Role of Institutional Quality. Indonesian Journal of Economics, Social, and Humanities, 1(2), 65-76.

Hartmann, D. (2014). Economic Complexity and Human Development: How Economic Diversification and Social Networks Affect Human Agency and Welfare. New York: Routledge.

Hartmann, D., Jara-Figueroa, C., Guevara, M., Simoes, A. ve Hidalgo, C. A. (2016). The Structural Constraints of Income Inequality in Latin America. Integration \& Trade Journal, 40, 70-85.

Hartmann, D., Guevara, M. R., Jara-Figueroa, C., Aristarán, M. ve Hidalgo, C. A. (2017). Linking Economic Complexity, Institutions, and Income Inequality. World Development, 93, 75-93.

Hausmann, R., Hidalgo, C. A., Bustos, S., Coscia, M., Chung, S., Jimenez, J., Simoes, A. ve Yıldırım, M. A. (2011). The Atlas of Economic Complexity Mapping Paths to Prosperity, Center for International Development at Harvard University.

Herzer, D., Hühne, P. ve Nunnenkamp, P. (2014). FDI and Income Inequality-Evidence from Latin American Economies. Review of Development Economics, 18(4), 778-793.

Hidalgo, C. A. ve Hausmann, R. (2009). The Building Blocks of Economic Complexity. Proceedings of the National Academy of Sciences, 106(26), 10570-10575.

Hidalgo, C. (2015). Why Information Grows: The evolution of Order, from Atoms to Economies. New York: Basic Books.

Hodgson, G. M. (2003). Capitalism, Complexity, and Inequality. Journal of Economic Issues, $37(2), 471-478$.

Johansen S. ve Juselius, K. (1990). Some Structural Hypotheses in A Multivariate Cointegration Analysis of the Purchasing Power Parity and the Uncovered Interest Parity for UK. Journal of Econometrics, 53, 211-44.

Johansen, S. (1988). Statistical Analysis of Cointegration Vectors. Journal of Economic Dynamics and Control, 12(2-3), 231-254.

Kapartzanis, P. (2018). Unlinking Causally Economic Complexity and Income Inequality (MSc Thesis). University of Ioannina, Ioannina.

Kaulihowa, T. ve Adjasi, C. (2018). FDI and Income Inequality in Africa. Oxford Development Studies, 46(2), 250-265.

Khan, I. ve Nawaz, Z. (2019). Trade, FDI and Income Inequality: Empirical Evidence from CIS. International Journal of Development Issues, 18(1), 88-108.

Kuznets, S. (1955). Economic Growth and Income Inequality. American Economic Review, $45(1), 1-28$.

Lapatinas, A. (2016). Economic Complexity and Human Development: A Note. Economics Bulletin, 36(3), 1441-1452.

Le Caous, E. ve Huarng, F. (2020). Economic Complexity and the Mediating Effects of Income Inequality: Reaching Sustainable Development in Developing Countries. Sustainability, 12(2089), 1-26. 
Lee, K. ve Vu, T. (2019). Economic Complexity, Human Capital and Income Inequality: A CrossCountry Analysis. MPRA Paper No. 94737, 1-31.

Moghadasi, L. S. (2018). The Study of Economic Complexity and GDP Effect on Inflation Rate and Income Inequality in Persian Gulf States 2002-2015. Mapta Journal of Mechanical and Industrial Engineering (MJMIE), 2(3), 31-39.

Morais, M. B., Swart, J. ve Jordaan, J. A. (2018). Economic Complexity and Inequality: Does Productive Structure Affect Regional Wage Differentials in Brazil?. U.S.E. Working Paper Series nr: 18-11, 1-59.

Nwosa, P. (2019). Income Inequality and Economic Growth in Nigeria: Implications for Economic Development. Acta Universitatis Danubius Oeconomica Special Issue 15(1), $108-116$.

Park, J. Y. (1992). Canonical Cointegrating Regressions. Econometrica: Journal of the Econometric Society, 119-143.

Penn World Table (2020, May1s). https://www.rug.nl/ggdc/productivity/pwt/.

Phillips, P. C. ve Hansen, B. E. (1990). Statistical Inference in Instrumental Variables Regression with I(1) Processes. The Review of Economic Studies, 57(1), 99-125.

Solt, F. (2019). Measuring Income Inequality Across Countries and Over Time: The Standardized World Income Inequality Database. SWIID Version 8.2, November 2019.

Stock, J. ve Watson, M. (1993). A Simple Estimator of Cointegrating Vectors in Higher Order Integrated Systems. Econometrica, 61(4), 783-820.

Şeker, A. (2019). Teknolojik Gelişme ve Yüksek Teknoloji İhracatının Ekonomik Karmaşıklık Endeksi Üzerindeki Etkisi: Türkiye Örneği. Yönetim ve Ekonomi: Celal Bayar Üniversitesi İktisadi ve İdari Bilimler Fakültesi Dergisi, 26(2), 377-395.

TheGlobalEconomy.com (2020, May1s). https://www.theglobaleconomy.com/.

The Observatory of Economic Complexity (2020, Nisan). https://oec.world/.

Vo, D. H., Nguyen, T. C. ve Tran, N. P. (2019). What Factors Affect Income Inequality and Economic Growth in Middle-Income Countries?. Journal of Risk and Financial Management, 12(1), 40, 1-12.

Zhu, S. ve Li, R. (2017). Economic Complexity, Human Capital and Economic Growth: Empirical Research Based on Cross-Country Panel Data. Applied Economics, 49(38), 3815-3828.

Zhu, S., Yu, C. ve He, C. (2020). Export Structures, Income Inequality and Urban-Rural Divide in China. Applied Geography, 115, 1-9.

Zivot, E. ve Andrews, D. (1992). Further Evidence of the Great Crash, the Oil-Price Shock and the Unit-Root Hypothesis. Journal of Business and Economic Statistics, 10, 251-270.

Zortuk, M. (2009). Economic Impact of Tourism on Turkey's Economy: Evidence from Cointegration Tests. International Research Journal of Finance and Economics, 25(3), 231-239. 